\title{
A cidade que nos olha: imagem e vestígio nos noturnos de Cássio Vasconcellos
}

Daniela Palma

Resumo: O ensaio propõe uma leitura do livro fotográfico Noturnos São Paulo (2002), de Cássio Vasconcellos, articulando considerações sobre a consistência imagética das fotografias urbanas que o compõem a questões associadas à memória do próprio dispositivo (da fotografia, do livro). O trabalho crítico, iluminado por autores como Didi-Huberman, Derrida, Benjamin e Merleau-Ponty, busca refletir sobre os vínculos transtemporais, sobre os fantasmas, que a imagem fotográfica comporta, atingindo, assim, seu próprio núcleo poético.

Palavras-chave: fotografia contemporânea; cidade; poéticas; Cássio Vasconcellos.

Abstract: The city that looks at us: image and trace in the photo-series Noturnos, by Cássio Vasconcellos - This paper proposes a reading of the photobook Noturnos São Paulo (2002), by Cassio Vasconcellos, articulating considerations about the imagetic consistency of urban photographs that form it and issues associated to the memory of the device itself and of the book/object. The critical work is supported by authors such as Didi-Huberman, Derrida, Benjamin and Merleau-Ponty; it seeks to reflect upon the transtemporal links, the phantoms that the photographic image encompasses, thus reaching its own poetic core.

Keywords: contemporary photography; city; poetics; Cássio Vasconcellos.

No horizonte de todas essas visões ou quase-visões está o próprio mundo que habito, o mundo natural e o mundo histórico, com todos os vestígios humanos de que é feito. 
Em 2010, algumas das imagens da série de vistas urbanas noturnas de Cássio Vasconcellos foram ampliadas ao formato de $5 \times 5$ metros para que cada uma ocupasse um dos nichos arquitetônicos do mezanino do edifício do prédio dos Correios, no centro de São Paulo. Era impactante ver as pequenas polaroides atingirem tais dimensões. Anteriormente, conhecia, de maneira dispersa, parte dessa série de noturnos, que o fotógrafo começara a produzir em 1998. Acabei fazendo o percurso inverso e busquei o livro, lançado em 2002, apenas com imagens de São Paulo.

A surpresa foi ter em minhas mãos um livrinho de pequenas dimensões, contrastando fortemente com a monumentalidade expositiva dos painéis de cinco metros. Um livro de aspecto artesanal que parecia tão fora dos padrões dos livros de fotografia. Passeando por suas páginas, certas impressões sobre aquelas imagens iam se formando, coisas que não haviam se sobressaído de forma mais incisiva na exposição. A impressão primeira é que eu não conseguia ver São Paulo ali, nenhum caráter documental naquelas fotografias. Não por achar irreconhecíveis os elementos da paisagem urbana representada. Grande parte deles era, sim, reconhecível - pensando em termos exclusivamente referenciais. Percebo que há nas fotos algo que mais as distancia, do que as aproxima, de seu suposto referente (a cidade), e não é algo visualmente presente nelas, mas que só alcanço pela sua visualidade. São ausências, vazios ali que precisariam ser nomeados.

Como admitir a existência do invisível na representação visual? Como dar tratamento analítico, em termos estéticos e de sentidos, para aquilo que a imagem não mostra; para os fantasmas dela? Um pensamento sobre a poética fotográfica parece apontar para abordagens que consigam ir além do visível.

Então, o exercício aqui proposto é o de olhar para as fotografias de Cássio Vasconcellos para além de formalismos e estruturas, para além dos volumes, para além do mimetismo, para além do referente - embora nada disso deva ser ignorado. É tentar enxergar significação também no que não pode ser visto - em suas sombras, em suas dobras, em sua insubstância, em suas ausências. Do visível, atingir o invisível. Pretende-se, com isso, não apenas refletir sobre possibilidades de contemplar a poética fotográfica, como também apontar para a ampliação das discussões sobre as figurações do urbano, tema desses noturnos.

\section{Ver e crer}

Merleau-Ponty chamou atenção para a relação entre visibilidade e tangibilidade: o que se pode ver é o que se pode tocar. Assim, a própria ideia de mundo, do que existe fora da gente, passa a ser entendida em função da relação sensorial ver-tocar. Mas, o filósofo já atentara: "meu corpo, como encenador da minha percepção, já destruiu a ilusão de uma coincidência da minha percepção com as próprias coisas". E continua ressaltando a distância entre o percebido e as coisas, "entre mim e elas, há, doravante, poderes ocultos, 
toda essa vegetação de fantasmas possíveis que ele só consegue dominar no ato frágil do olhar" (MERLEAU-PONTY, 2009, p. 20).

Dessa fragilidade da faculdade de olhar, que permite considerar como existentes o visível e o invisível, Didi-Huberman identifica a modalidade da visão. Precisamente, as duas formas que essa atividade humana assume; a separação entre dois estados que definem o ver - uma cisão inelutável, adjetivo de uma expressão Joyce, em Ulisses, "inelutável modalidade do visível" (ineluctable modality of the visible). Essa dupla natureza apresenta-se inelutável, quando nos damos conta de que o visível não demarca apenas presença, mas também ausência, ou, "quando ver é sentir que algo inelutavelmente nos escapa, isto é: quando ver é perder" (DIDI-HUBERMAN, 2010, p. 34). E, nesse ponto, recorre à figura da imagem que nos olha: essas latências, ao não nos deixarem vê-las, estabelecem uma inversão de ponto de vista; são elas que nos olham.

A cisão do ato de ver abre essa experiência em duas - a de ver o artefato, a evidência, o volume; e a de ver o vazio, as latências do objeto visual. Essa partição acabou por gerar duas posturas: a tautológica, que fica aquém da cisão, apegando-se unicamente à evidência; e a da crença, que vai além da cisão, dando existência ao invisível, mas não se relacionando com a imagem propriamente, a não ser como objeto de devoção.

O autor desenvolve posições críticas a essas duas posturas. Com relação à primeira, considera o apego ao artefato um apego a uma "verdade rasa", como um indivíduo que frente a uma tumba, por exemplo, só vê um paralelepípedo de pedra. Há aí uma recusa tola ao que está "por baixo, escondido, presente, jacente" ao objeto; à "temporalidade do objeto, [a]o trabalho do tempo ou da metamorfose do objeto, [a]o trabalho da memória - ou da obsessão - no olhar" (ibid., p. 39).

Na segunda postura, o autor identifica uma vitória da obsessão sobre a linguagem. Uma relação dedutiva do ser-que-olha com a imagem; já que se baseia em uma espécie de "modelo fictício no qual tudo - volume e vazio, corpo e morte-poderia reorganizar, substituir, continuar a viver no interior de um grande sonho" (ibid., p. 40). Realiza-se aí uma operação de superação imaginária do que efetivamente se vê, o ato de ver condensa-se em dogma, nasce então uma relação de messianismo entre a imagem e quem a olha.

A cisão do ver não se define nem como arcaica, nem como moderna (ou modernista); "essa modalidade atravessa simplesmente a longa história das tentativas práticas e teóricas para dar forma ao paradoxo que a constitui" (ibid., p. 34). Faz referência à distinção entre imago e vestigium, estabelecida por teólogos medievais. Estes consideravam que o que podemos ver, a imagem, deve ser visto sempre como "o traço de uma semelhança perdida, arruinada, a semelhança de Deus perdida no pecado", o vestígio (ibid., p. 35). A imagem dá existência ao vestígio, o vestígio só ganha presença pela imagem.

A postura de não recusar a cisão do ver, de aceitar a distinção entre imagem e vestígio, pode ser entendida como uma volta à noção de aura. O conceito de aura recebeu leituras que o reduziram a um fenômeno de fascinação, mas Didi-Huberman destaca 
uma definição que aparece em várias das obras de Benjamin: "é a figura singular, composta de elementos espaciais e temporais: a aparição única de uma coisa distante, por mais próxima que ela esteja" (BENJAMIN, 1993a, p. 101; 1993b, p. 170).

Essa aparição do distante dotaria a coisa olhada de um "poder de levantar os olhos", na metáfora de Benjamin. O que vemos é o que nos olha, e essa sobreposição de perspectivas é permitida pela leitura do objeto artístico como algo que foi perpassado pelo tempo: a imagem como artefato é matéria e pressupõe trabalho - matéria e trabalho, dois elementos que inserem temporalidade.

A aura, então, seria essa capacidade de a matéria artística conotar, criando o efeito de presentificar o que está ausente, ou seja, de portar memória. Assim, a relação cultual, aurática, pode ser entendida como o ato de se deixar levar pela "trama de singular de espaço e tempo" da arte. Benjamin aponta que essa possibilidade de entrelaçamentos de diferentes trilhas temporais e perspectivas seria fonte da própria poesia. Além disso, ao usar a figura do objeto que "levanta os olhos", o autor dota a imagem de alteridade, o que em si comporta o estranhamento (outra potência poética).

A arte serviu inicialmente à magia como produtora de objetos com valor de culto. A aura estaria na origem da noção de imagem - que se ligava à magia. Mas, o que está na origem nunca se esvai, não se pensa aqui em origem como um começo que se pode historiograficamente apontar, mas, como a fonte de um rio, na analogia de Benjamin, a partir da qual a correnteza carrega seus sintomas - "turbilhão do rio".

Pode-se recorrer também, para pensar na noção de origem, à différance, de Derrida, trazendo-a para o campo da reflexão sobre as imagens. Toma-se o termo - que não é um conceito, segundo o autor - para refletir sobre as dinâmicas sígnicas, como cadeia de significados, engendrada por dois movimentos: temporização (postergação de significados) e espaçamento ("não ser idêntico, ser outro, discernível") (DERRIDA, 1991, p. 39).

Esses movimentos de devir-tempo e devir-espaço criam fluxos de significados constantes; sobre os textos, atuam forças (ausentes) contrastantes. Em diálogo com Nietzsche, Derrida diz que a diffèrance poderia se referir a uma "discórdia 'ativa', em movimento, de forças diferentes e de diferenças de forças" (ibid., p. 50). Assim, a noção de origem não é tomada de maneira plena, situada, mas estruturada, pois ela é pensada no movimento que a produz.

Quando Didi-Huberman afirma que o conceito de aura foi uma forma de Benjamin nomear uma qualidade antropológica, originária da imagem, podemos considerar essa "qualidade originária" em formação no próprio "turbilhão do rio" ou no movimento da différance. O declínio da aura na modernidade, apontado por Benjamin, seria um processo de decadência ou de inflexão, não de desaparição (DIDI-HUBERMAN, 2011, p. 346). De muitas formas, a pulsão da aura parece se manifestar, sob interpretações metafísicas ou não, até nas imagens mecânicas como a fotografia: das fotos-relicário no século XIX, passando pelo pictorialismo, chegando até parte das leituras indiciais que a imagem fotográfica recebeu na segunda metade do século XX. 
Didi-Huberman propõe uma postura crítica que se poste na própria cisão do olhar; entre o percebido e o ausente, o artefato e a aura, a imagem e o vestígio. Ecoando Benjamin, pensa a reinserção da noção de aura no objeto artístico, no entanto, sem caráter religioso ou messiânico; ressalta o sentido literal de aura, que, para os gregos, designava "apenas uma exaltação sensível - portanto material, antes de destacar seu sentido 'psíquico' ou 'espiritual'" (DIDI-HUBERMAN, 2010, p. 166).

Aceitar "a imanência visual e fantasmática dos fenômenos ou objetos" não significa tomá-la como "signo enviado desde sua fictícia região da transcendência", mas pensá-la como possibilidade de novas formas de experimentar o sublime (ibid., p. 158). Articula, assim, a ideia de secularização da aura, por meio de uma dialética entre o visível e o invisível, e que este não seja definido como sobrenatural, mas como o sintoma do que está distante ou ausente.

A suposição da existência da aura na modernidade vincula-se à memória, na heterogeneidade de tempos, no potencial anacrônico dos objetos artísticos (DIDIHUBERMAN, 2011). A imagem aurática é perpassada pelo tempo e a revalorização disto não é exclusiva missão dos artistas - já que o tempo estará sempre impregnado nos objetos artísticos -, também depende muito do trabalho crítico.

Há, assim, a proposta de novas posturas interpretativas abertas à relação sincrônica e entre o agora e o outrora nos objetos artísticos, ver (e produzir) a imagem dialética é aceitar o "chamado a Outrora". É tomar as imagens como fantasma e sintoma, em constante movimento de montagem de sentidos (DIDI-HEBERMAN, 2013). Essa postura de intérprete pode ser definida como uma espécie de retomada da imaginação como expediente de leitura de vestígios, permitindo que tempos e espaços atuem uns sobre os outros, "por colisões ou por fusões, por rupturas ou por metamorfoses..." (DIDI-HUBERMAN, 2003, p. 149; tradução minha).

\section{Imagens da noite (ou o que vemos)}

O livro Noturnos São Paulo, de Cássio Vasconcellos, é composto de 96 fotos, produzidas entre 1988 e 2002, com uma câmera automática Polaroid SX-70, da década de 1970. Posteriormente, o fotógrafo continuou a série, com vistas de outras grandes cidades do mundo. Vamos nos deter aqui apenas nas imagens que constam no livro, que apresenta uma edição do material sobre São Paulo.

Para produzir essas vistas, o artista não recorreu a intervenções físicas ou químicas nas matrizes ou nas cópias: pura fotografia direta. Para fotografar, utilizou filtros e fontes de luz - lanternas, farol do carro, holofote - para projetar fachos de luz, com ou sem cores, nos objetos. Depois, digitalizou as matrizes e as imprimiu em papel de algodão neutro, com tinta mineral, resultando em cópias de longa durabilidade. 
A Polaroid é associada a imagens de pouca definição e cores saturadas. Vasconcellos tira proveito dessas características da técnica para obter uma visualidade etérea, mística. A definição baixa, os contornos quase inexistentes, o foco impreciso, imagens que parecem fora de registro e, ainda, no livro, a impressão em papel poroso reforçam a textura granulada das fotografias noturnas - imagens que parecem em dissolução: um impressionismo da noite que ganha dimensão simbólica. As limitações técnicas para a fotografia noturna transmutam-se aqui na própria essência da noite - a granulação, a reticulação, como estado de dissolução.

Nietszche disse que o ouvido é o órgão humano do medo e a música seria, por excelência, a arte da noite e da penumbra. Pois, temos aqui a fotografia, uma arte essencialmente da luz. A representação da penumbra e do escuro, pela luz, traduziuse, assim, não na tentativa de dar-lhe contornos - como em uma iluminada paisagem diurna -, mas na própria decomposição da superfície da imagem. A noite ganha então leitura poética, não pela escuridão, mas pela dissolução dos vestígios da luz na própria fragmentação da imagem.

O dia ilumina, dá contornos, solidez, encorpa os volumes; a noite liquefaz, esgarça a trama, fragiliza as certezas. O dia é apolíneo, dos sonhos, dos ideais clarificados, das distinções, da imagem; a noite, dionisíaca, da visão cega, da embriaguez, da música. A simbologia nasce da própria dualidade que Nietszche apontou na essência do desenvolvimento artístico: o figurador plástico, representado por Apolo, e a arte não-figurada, simbolizada por Dionísio (NIETZSCHE, 1992).

Os noturnos de Vasconcellos são, no entanto, vigorosos nas cores. A luz projetada atribui um colorido, que é intensificado pela Polaroid. Mais do que iluminar, a luz colore, fazendo explodir nas imagens uma dimensão pictórica. Cria-se uma tensão entre o apolíneo e o dionisíaco: a luz que possibilita à figuração não se anular na escuridão, ao mesmo tempo, conduz a imagem para os campos da abstração e do irrealismo pela hipercoloração artificial.

As cores lançadas pelas fontes de luz ou obtidas pelo uso de filtros destoam dos tradicionais cinzas urbanos, são cores que carregam organicidades e transcendentalidade: o vermelho da carne, do sangue e do fogo; o verde das forças da natureza; o amarelo solar e corpóreo; o azul transcendental do oceano e do céu, ou tantos outros sentidos que se pode extrair da coloração. Didi-Huberman observa a capacidade de a pintura, por meio da cor, encarnar, ou seja, a superfície da tela, por meio da aplicação de tintas, assumiria aparência de entidade viva, uma vida que tem existência pela própria pintura (DIDI-HUBERMAN, 1985).

A possibilidade de a cor encarnar uma superfície ganha aqui dimensão na fotografia. As cores não são simplesmente despejadas sobre objetos, não são coberturas, roupas, capas. Ferro, pedra, concreto, vidro, vegetação adquirem força visceral e candente, ao avermelharem-se, e criam tensão no contraste com o azul infinito ou o verde natural. 
Uma enorme peça de ferro ilumina-se de vermelho encarnado e transmuta-se em uma enorme boca aberta e, por dentro dela, conseguimos ver um fundo azul do cenário de prédios envidraçados. Lápides com figuras sacras cristãs flamejam, enquanto verdeja ao fundo uma cidade distante, imprecisa, selvagem. Monumentos manchados, um prédio em ruínas, um relógio enferrujado, todos esverdeados: a passagem do tempo, o processo natural. As possibilidades de jogos ${ }^{1}$ de sentidos pelas combinações de cores nos Noturnos são infindáveis, mas, de modo geral, as cores acionam a natureza como um fantasma no cenário urbano - dos artefatos da cidade, pulsam forças naturais.

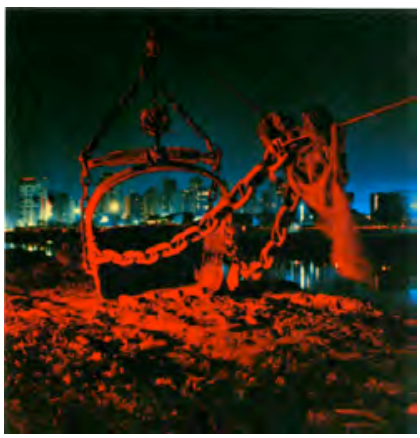

Fig. 1. Marginal Pinheiros \#9. Fonte: Vasconcellos (2000).

Essas cores vitais fundem-se a vultos, não há apenas penumbra pálida, mas escuridão total também. Os vultos funcionam como pressupostos, deixam marcas sutis das formas de algumas presenças, mas não as explicitam. Pressupõem-se um viaduto, uma estátua, um volume. O escuro também cria a indistinção de planos, que parecem achatados, empastelados, estrutura e superfície fundem-se. Há a anulação da geometrização perspectiva do espaço. O volume de um edifício desaparece completamente, a lateral do prédio dissipa-se nas sombras. Sem volume, a construção representada é reduzida a uma fachada espectral, como uma película, cheia de janelas, que ligam a uma dimensão invisível na imagem.

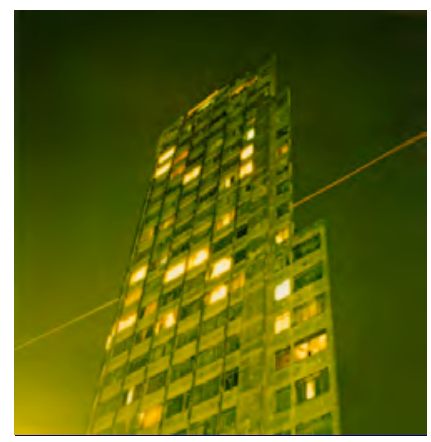

Fig. 2. Rua Mauá \#3.Fonte: Vasconcellos (2001).

1 Uso, ao longo do texto, deliberadamente as palavras jogo, jogar, brincar; aludindo à ideia de jogo em Derrida para se referir às relações entre as diferenças que brotam do movimento da différance. 
As luzes estouradas, as cores intensas em meio à penumbra e a falta de contornos criam imagens em que a solidez do registro se esvai. Essas imagens parecem não se consolidarem, são fugidias, sorrateiras, apresentam "conjunções fulgurantes" (usando aqui a expressão de Benjamin), aparecem aos nossos olhos e se vão, como fantasmas ou relâmpagos. Imagens-aparição, ao invés de imagens-registro.

Todos esses expedientes de composição imagética da noite urbana criam (e são afetados por) oposições: manchas e brilhos, luz e sombra, estrutura e superfície, acabado e inacabado, sólido e esfumaçado, decrepitude e florescência, natureza e artefato. Um movimento de significados do qual jorram diferenças, que se colidem, fundem-se, metamorfoseiam-se.

\section{Vestígios fotográficos (ou o que nos olha)}

No texto de abertura do livro, Vasconcellos diz que suas imagens são "silenciosas como a noite tende a ser" e completa: "não porque não há pessoas nelas, afinal meu objetivo foi captar os vestígios humanos e não personagens. E sim porque a vida e a inquietação da cidade estão apenas implícitas no cenário" (VASCONCELLOS, 2002, p. 8).

As paisagens urbanas, como gênero de imagens, não dão visibilidade às pessoas, a não ser de forma secundária. Ao trabalhar com escalas que representam áreas mais amplas, a presença humana é figurativamente esfacelada. Podemos, na maior parte das vezes, somente supor a presença de pessoas ali. A paisagem é a imagem de um vestígio ("traço da semelhança perdida"), sintoma do humano.

Vasconcellos, por meio de suas representações do espaço urbano, nos propõe olhar para o que, na aparência, não tem vida, e, a partir destas superfícies sem vida, ver "a vida"; a partir do silêncio, ver "a inquietação". Olhar os vestígios e ver, não as próprias essências, mas a "semelhança perdida" delas. Se tomarmos outros trabalhos do fotógrafo, notamos que questões similares também os permeiam. Séries com escalas que reduzem a figura humana a pequenos pontos, manchas, ou, simplesmente, a desintegram - vistas aéreas pulsantes, panorâmicas horizontais, panorâmicas verticais.

Até mesmo em uma série de retratos que fez, fotografando com Polaroid rostos de personagens de filmes, a partir da tela de um televisor, observamos a dissolução da forma humana. As faces iluminadas e pouco definidas esforçam-se para sair da penumbra que toma a imagem - um mezzotinto, em que "a luz se esforça, laboriosamente, para sair da sombra", aludindo à representação oitocentista de aura humana nos portraits (BENJAMIN, 1993a, p. 99) -, os olhos estão cerrados, aparências mortas, borradas, fantasmáticas. Todas essas imagens recusam-se a nos mostrar imageticamente a vida, é sempre um jogo de implícitos. Da vida, do humano, as imagens mostram apenas os vestígios.

O fotógrafo destaca ainda a sonoridade, na composição dos noturnos, por meio da linguagem muda das imagens: a ausência de som como recurso compositivo. 
Associa o silêncio a uma condição da noite e ao estado vazio de sua cidade - outro elemento que aponta para uma concepção aurática de imagem. Didi-Huberman refere-se ao silêncio como qualidade fundamental da concepção benjaminiana de secularização da aura, pois "o homem da 'reprodutibilidade técnica', em meio ao ruidoso labirinto das mediações, das informações, deve algumas vezes fazer silêncio e usufruir a inquietante estranheza do que lhe retorna como aura, como aparição alterante" (DIDI-HUBERMAN, 2011, p. 347-348)

Olhar a noite fulgural, estranha, com torres vermelhas e céus amarelos, no silêncio contemplativo de quem vê uma assombração: essa parece ser a proposta do fotógrafo. Experimentar o sublime por meio da contemplação e do silêncio, postura que aponta para uma reconstituição da aura. Mas, a fotografia tem em si a experiência de aura para ser restaurada?

Os noturnos brincam de buscar essa aura perdida (ou caída) nas outras artes: a religiosa, o clássico, até em propostas e estilos modernos que refletiram sobre as fronteiras entre real e imaginário, mundo e arte. Estabelecem, assim, uma espécie de diálogo - leve, sem severidade - entre a fotografia e outras linguagens plásticas. A própria ideia de colorir com a projeção de luz, como um pictorialismo invertido, joga com a relação histórica entre pintura e fotografia.

Nas imagens dos noturnos, podemos encontrar, espalhadas, evocações mais pontuais, de forma mais ou menos relativamente explícita: objetos tumulares, colunas e esculturas de inspiração neoclássica, composições e uso de recursos que fazem alusões a Van Gogh, Monet, De Chirico e talvez outros artistas e estilos. Podemos brincar de folhear o livro e tentar encontrar nas imagens essas ligações com a temporalidade histórica da arte.

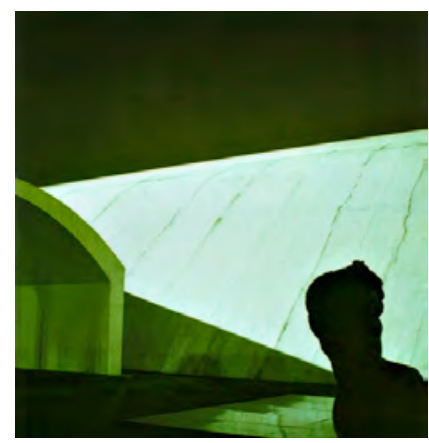

Fig. 3. Memorial da América Latina \#1. Fonte: Vasconcellos (2001).

Apesar desse jogo de referências, o fotógrafo parece entender que a aura não se cria por um processo de imitação, de anulação do que é próprio do fotográfico. Para refletir sobre isso, vamos tomar os noturnos não apenas como imagem, mas também em sua condição de objeto e dispositivo. No âmbito desses produtos da "reprodutibilidade técnica", o que seriam exatamente os objetos, a partir dos quais, poderíamos pensar a experiência da unicidade? 
No caso do Noturnos, o que chega a mim, o que manuseio, é o livro. Trata-se de um livro de pequenas dimensões, $17 \times 14 \mathrm{~cm}$, embora maior que o formato dos originais em Polaroid. O livro tem toque e acabamento um pouco selvagem, quase que expondo uma "artesanalidade" intencional - artesanal, entendido como aquilo que é trabalho humano e se mostra como trabalho humano, mas sem apagar totalmente a ligação do objeto manufaturado com a matéria original, com a própria natureza.

O papel poroso e fosco difere do acetinado dos couchês convencionais, industrializados e homogêneos, dos livros de fotografia. Papel espesso, acartonado, teso, que não permite o movimento de folhear dos livros de leitura, é preciso mudar de página sem flexioná-la, como um álbum de fotografia. Sim, um pequeno álbum que permite colocar, em cada verso de folha, uma foto, mas nem todos eles estão completos - ora tem imagem só na frente, ora, só no verso, ou, nos dois lados, como os nossos álbuns pessoais, dos quais usualmente tiramos algumas fotos do lugar e não as devolvemos, perdemo-las. O livro, pensado como álbum, consigna (reúne signos) imagens, não as isola, e elabora-se como montagem, colocando "o múltiplo em movimento" (DIDI-HUBERMAN, 2003, p. 151; tradução minha).

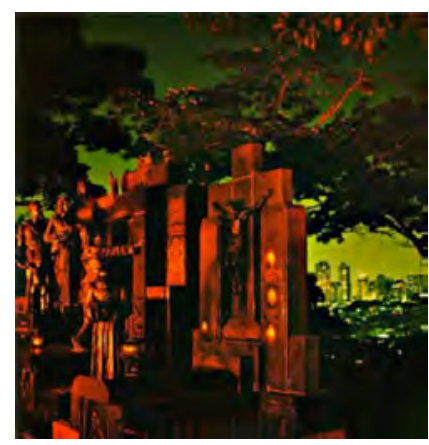

Fig. 4. Cemitério do Araçá \#3. Fonte: Vasconcellos (2001).

Além disso, o álbum de fotografias, que preserva reminiscências, tem forte conotação relicária. O tamanho diminuto reforça a demarcação de um objeto que tende ao privado, que quase cabe na mão e é para ficar junto à pessoa que o olha e possui. O pequeno formato do receptáculo que guarda imagens-relíquias, imagens-memoração, remete à ideia de possessão. O caráter relicário da fotografia liga-se a uma operação de memória, à crença em sua capacidade de presentificar. O vínculo da fotografia com uma ideia de passado, não desaparece, a própria passagem do tempo adere à imagem, "essas impressões, com o passar do tempo se tornam etéreas, nubladas, longínquas" (KOSSOY, 1998, p. 44).

Essa capacidade de atuar como relicário pode ser uma chave para pensar a potência aurática da fotografia. O estudo de Frade (1992), sobre os discursos sociais acerca da fotografia nos momentos próximos ao surgimento da técnica, identifica a relação cultual 
e de espanto com as imagens fotográficas. Curiosamente, a crença no caráter objetivo da tecnologia acabou por possibilitar leituras metafísicas. Talbot, homem da técnica e da ciência do século XIX, falava na exclusão total da participação humana no processo de realização fotográfica, o ideal do automatismo. A partir da eliminação do sujeito produtor da imagem, quem daria as cartas seria a própria natureza - a câmera considerada apenas como instrumento para a realização de um processo natural.

Se é a natureza que escreve na superfície fotográfica, então aquela adere à própria matéria fotossensível. O objeto fotografado e a imagem estariam, assim, em uma relação de contiguidade e causalidade - antecipando a compreensão semiótica de relação indicial. Da objetividade para a magia, um pulo, "por meio da experimentação fotográfica, a fronteira entre positivismo e magia torna-se bem tênue..." (DIDI-HUBERMAN, 1998, p. 75; tradução minha). Se a fotografia emana do objeto, logo adquire valor de relíquia, como um sudário.

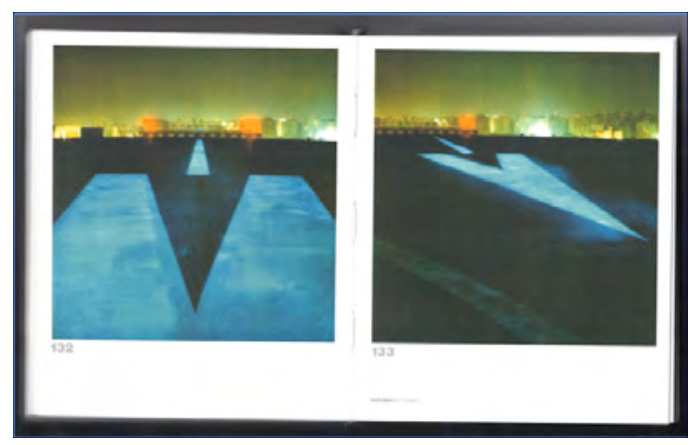

Fig. 5. Noturnos São Paulo (páginas do livro). Fonte: Vasconcellos (2002).

Podem ser citados diversos exemplos, bem conhecidos, de concepções do século XIX que tomavam a fotografia como processo mecânico de implicações naturais e espirituais: o psiquiatra Baraduc, que defendia a existência de "emanações fluídicas" da alma humana passíveis de serem captadas pela fotografia; ou, ainda, a ideia de Balzac de que os corpos da natureza são compostos por camadas de espectros e, quando fotografado, o objeto perderia um destes espectros, que ficaria retido na chapa fotográfica.

A noção de fotografia como relíquia liga-se fundamentalmente a uma presença (a crença nela) invisível da natureza no artefato - a natureza física, a natureza espiritual. Além das invisibilidades, identifica Frade, a fotografia espantava por sua capacidade de lidar com uma das mais divinas potências naturais, "a força do sol ou se, preferimos, o poder da luz" (1992, p. 71).

Dizer que surpreende pela luz equivale a dizer que surpreende (ou espanta) também pela sombra. Frade aponta que até mesmo Talbot chegou a "vacilar" nesse sentido, escrevendo em seu diário que a obscuridade seria o elemento constitutivo fundamental da fotografia - um processo que poderia ser nomeado skiagráfico (escrita da sombra). 
Da ambivalência luz-sombra, o inglês acabou por preferir a luz para definir a técnica, pois a escuridão seria falha; a luz, graça (ibid., p. 72-73).

Se com as raridades antigas, estabelecia-se mais uma relação de adoração, as fotografias-relicário podem ser pensadas como possessão, como aprisionamento da imagem do outro junto a mim - o que, em uma visão não secularizada, poderia ser associado à bruxaria. A fotografia como "relíquia secularizada" ganha valor aurático uma aura vinculada à capacidade de as imagens fotográficas acionarem processos de (re)memoração por meio dos fantasmas, nos quais se crê, aderidos ao artefato.

Essa perspectiva crítica permite que se amplie a própria concepção de objeto e, aqui, poderíamos tomar não apenas o livro, mas também o material que foi expelido da câmera Polaroid. Neste caso, é possível pensar tanto nas chapas resultantes, como no dispositivo que as gerou - o que inclui o aparato tecnológico e os rastros deixados pelo processo fotográfico nas imagens.

A Polaroid é uma câmera típica do universo íntimo, familiar, instantânea (o mais instantâneo dos processos), feita para amadores, sem regulagens complicadas, fácil de operar. Em entrevista, Vasconcellos recorda que, quando ainda era menino, o pai levara uma câmera Polaroid para casa, o fotógrafo guardou a lembrança da sensação de fascínio que aquele objeto Ihe causou. É muito comum que as referências à Polaroid expressem afetividade e fascinação. A começar pelo próprio manuseio de alguns dos modelos da câmera (esse usado por Vasconcellos, inclusive) - ela se abre e se mostra. Em funcionamento, a máquina cospe o papel e a imagem faz sua mágica aparição diante dos olhos humanos. Talvez seja o processo fotográfico que mais nos permita experimentar a sensação da magia propiciada pela instantaneidade, de assistir a aparição única, o evento único.

A imagem da Polaroid é objeto único, voltando à questão da unicidade que permeia a discussão sobre a aura. Diante de uma dessas fotos não consigo ignorar a fugacidade do processo que a gerou, como se a própria experiência da aparição imagética, única, se fundisse à matéria fotográfica e a dotasse de aura. Nos noturnos que tenho em minhas mãos, mesmo não me sendo oferecido diretamente aqueles objetos singulares produzidos pela câmera (as matrizes), permanece a memória e o devir da aparição única, que adere às imagens e transporta aos meus olhos essa sensação, o sintoma dessa experiência.

\section{Cidade-aparição}

Os grandes painéis nos vãos do prédio dos Correios já haviam acionado o efeito cidade-que-aparece-aos-meus-olhos - essa aparição de toque mágico que reacende uma postura contemplativa. A monumentalidade espantava, mas, ao mesmo tempo, as imagens fundidas às estruturas arquitetônicas do lugar de passagem dispersavam-se em meio a tudo mais. Era como uma intermitência (o espaço que "pisca") entre figuras de espanto e o empastelamento perceptivo que define o processo de "banalização do espaço", como descreve Benjamin (1991, p. 188), ao refletir sobre a experiência urbana. A mudança 
de escala no livrinho reforça as marcas de intimidade e unicidade do objeto, permitindo a reinterpretação das imagens, ao inseri-las no regime da memória.

Ao dar aparição à sua cidade fantasmática, em meio à noite paulistana, Vasconcellos parece propor a (re)sublimação não apenas da fotografia, mas também do próprio espaço urbano, por meio de suas polaroides. A cidade-aparição forma-se na perda de densidade figurativa dos noturnos: a paisagem ganha fluidez, vira assombração, vestígio e assume sua faceta ficcional. A metrópole feia e caótica parece nas imagens de Vasconcellos estranhamente bonita, estranha, porque carrega uma beleza que não se consolida, que foi, é e será uma aparição.

O vestígio ou sintoma da aparição única, grudada nos instantâneos da Polaroid, despeja ante nossa vista uma experiência de lugar. Não de espaço, no sentido de suas coordenadas objetiváveis e detalhes urbanísticos de composição de paisagem, mas de um lugar imaginário, um devir-espaço - que se supõe ser a cidade de São Paulo - onde forças da natureza se fundem ao artefato humano (o artefato da cidade, o dispositivo da fotografia).

Esse lugar imagético, imperfeito e poético, onde explode a natureza, surpreende-nos e fascina, mas não por estar além do humano e, sim, por compreendermos que ele é o ato de uma subjetividade, a do fotógrafo, em contato (ou confronto) com outras subjetividades, as nossas - nós, que podemos ver a imagem e sentir sua materialidade, e que nos deixamos ser conduzidos através de uma "trama singular, estranha, de espaço e tempo".

A imagem fotográfica tomada como objeto que condensa e conflita sensorialidade e memoração propicia um alargamento do campo de produção e crítica. A poesia está no cerne da imagem aurática, a memória é elemento que possibilita a experiência do sublime. É muito comum a vinculação entre memória e registro, ressaltando o caráter documental, pois aqui apontamos para a ligação estreita entre memória e imaginário, acionada na cadeia de sentidos tecida a partir do objeto artístico.

Daniela Palma é docente do Departamento de Linguística Aplicada do Instituto de Estudos da Linguagem/Unicamp e pesquisadora do Núcleo de Estudos Interdisciplinares sobre Imagem e Memória do Laboratório de Estudos sobre Etnicidade, Racismo e Discriminação (Neiim-Leer/USP). Possui doutorado pela Escola de Comunicações e Artes/ USP (2010).

dpalma@iel.unicamp.br 


\section{Referências}

BENJAMIN, W. Charles Baudelaire: um lírico no auge do capitalismo. Tradução de José Carlos M. Barbosa e Hemerson A. Baptista. São Paulo: Brasiliense, 1991

Pequena história da fotografia. In: Magia e técnica, arte e política. Tradução de Sergio Paulo Rouanet. São Paulo: Brasiliense, 1993a, p 91-107.

A obra de arte na era de sua reprodutibilidade técnica. In: Magia e técnica, arte e política. Tradução de Sergio Paulo Rouanet. São Paulo: Brasiliense, 1993b. p. 165-196.

DERRIDA, J. Margens da filosofia. Tradução de Joaquim T. Costa e Antônio M. Magalhães. Campinas: Papirus, 1991.

DIDI-HUBERMAN, G. La peinture incarnée (suivi de Le Chef-d'oeuvre inconnu, d' Honoré de Balzac). Paris: Minuit, 1985.

La photographie scientifique et pseudo-scientifique. In: LEMAGNY, J.-C.; ROUILLÉ, A. (dir.). Histoire de la Photographie. Paris: Larousse-Bordas, 1998.

Images malgré tout. Paris: Minuit, 2003.

O que vemos, o que nos olha. Tradução de Paulo Neves. São Paulo: Editora 34, 2010.

. Ante el tiempo: historia del arte y anacronismo de las imágenes. Tradução de Antonio Oviedo. Buenos Aires: Adriana Hidalgo, 2011.

A imagem sobrevivente: história da arte e tempo dos fantasmas segundo Aby Warburg. Tradução de Vera Ribeiro. Rio de Janeiro: Contraponto, 2013.

FRADE, P. M. Figuras do espanto: a fotografia antes de sua cultura. Porto: Asa, 1992.

KOSSOY, B. Fotografia e memória: reconstituição por meio da fotografia. In: SAMAIN, E.(org.). O fotográfico. São Paulo: Hucitec, 1998, p. 41-47.

MERLEAU-PONTY, M. O visível e o invisível. Tradução de J. A. Gianotti e Armando Mora D'Oliveira. São Paulo: Perspectiva, 2009.

NIETZSCHE, F. O nascimento da tragédia ou Helenismo e Pessimismo. Tradução de J. Guinsburg. São Paulo: Companhia das Letras, 1992.

VASCONCELLOS, C. Noturnos São Paulo. São Paulo: Bookmark, 2002. 